\title{
Single VDTA Based Dual Mode Single Input Multioutput Biquad Filter
}

\author{
Rajeshwari Pandey, Neeta Pandey, and Navin Singhal \\ Department of Electronics and Communication Engineering, Delhi Technological University, Delhi 110042, India \\ Correspondence should be addressed to Rajeshwari Pandey; rajeshwaripandey@gmail.com
}

Received 14 June 2016; Revised 9 September 2016; Accepted 3 October 2016

Academic Editor: Durga Misra

Copyright (C) 2016 Rajeshwari Pandey et al. This is an open access article distributed under the Creative Commons Attribution License, which permits unrestricted use, distribution, and reproduction in any medium, provided the original work is properly cited.

\begin{abstract}
This paper presents a dual mode, single input multioutput (SIMO) biquad filter configuration using single voltage differencing transconductance amplifier (VDTA), three capacitors, and a grounded resistor. The proposed topology can be used to synthesize low pass (LP), high pass (HP), and band pass (BP) filter functions. It can be configured as voltage mode (VM) or current mode $(\mathrm{CM})$ structure with appropriate input excitation choice. The angular frequency $\left(\omega_{0}\right)$ of the proposed structure can be controlled independently of quality factor $\left(Q_{0}\right)$. Workability of the proposed biquad configuration is demonstrated through PSPICE simulations using $0.18 \mu \mathrm{m}$ TSMC CMOS process parameters.
\end{abstract}

\section{Introduction}

The ever shrinking feature size of devices on ICs and consequential reduction of power supply voltage poses serious challenges to analog design such as reduced input common mode range, output swing, and linearity. This can be handled by operating in the current domain, as current mode circuits are designed for lower voltage swings. Therefore, over the last few decades, current mode (CM) processing has evolved as an alternative design technique [1] and has resulted in emergence of numerous active building blocks (ABBs) [2] such as differential difference current conveyor transconductance amplifier (DDCCTA) [3], current difference transconductance amplifier (CDTA) [4], current feedback operational amplifier (CFOA) [5], operational transresistance amplifier (OTRA) [6], differential input buffered transconductance amplifier (DBTA) [7], current difference buffered amplifier (CDBA) [8], current conveyor transconductance amplifier (CCTA) [9], and voltage differencing transconductance amplifier [10] which are used for realization of various signal processing and generation circuits. Among these, the voltage differencing transconductance amplifier (VDTA) is a recently introduced active element [11]. The VDTA is a voltage input current output $\mathrm{ABB}$ with two transconductance gain stages. It provides electronic tuning ability through its transconductance gains. Thus, the VDTA is one of the most suitable ABBs for easy and compact CMOS implementation [12] of signal processing and generating circuits.

Electronic filters are essential building block of communication and instrumentation systems. A variety of VDTA based biquadratic filters are available in literature [10-18] which can be classified as single input multioutput (SIMO) [11-14, 18], multi-input single output (MISO) [15-17], and multi-input multioutput MIMO [10] filter configurations. These filters can further be classified as voltage mode [10, 13 , 17], current mode [11, 12, 14-16], and dual mode [18] structures. A detailed comparison of these structures is given in Table 1.

It may be noted from Table 1 that only a single VDTA based dual mode SIMO structure is available in literature and it uses five passive components. In this paper, a new single VDTA based SIMO-type dual mode biquad filter using four passive components is proposed. The proposed structure provides either voltage or current outputs through proper selection of input excitation. The proposed structure realizes three standard filter functions, namely, LP, HP, and BP, with independent $\omega_{0}$ and $Q_{0}$ tuning feature. Proposed circuit configuration also offers low passive sensitivities. The rest of the paper is organised as follows: In Section 2, detailed circuit description is presented. The circuit behaviour in 
TABLE 1: Comparison of the proposed work with the previously reported work.

\begin{tabular}{|c|c|c|c|c|c|c|c|}
\hline Ref. & $\begin{array}{c}\text { Number } \\
\text { of } \\
\text { inputs }\end{array}$ & $\begin{array}{l}\text { Simultaneous } \\
\text { outputs }\end{array}$ & $\begin{array}{l}\text { Standard } \\
\text { filter } \\
\text { functions }\end{array}$ & $\mathrm{VM} / \mathrm{CM}$ & $\begin{array}{l}\text { Active blocks } \\
\text { used }\end{array}$ & $\begin{array}{c}\text { Passive } \\
\text { components }\end{array}$ & $\begin{array}{l}\text { Orthogonal tunability of } \omega_{0} \\
\text { and } Q_{0}\end{array}$ \\
\hline$[10]$ & Two & Two & LP, HP, BP & $\mathrm{VM}$ & Two & Two C & No \\
\hline [11] & One & Three & LP, HP, BP & $\mathrm{CM}$ & Two & Two C & No \\
\hline [12] & One & Three & LP, HP, BP & $\mathrm{CM}$ & One & $\begin{array}{c}\text { Two C; One } \\
\text { R }\end{array}$ & Yes \\
\hline [13] & One & Five & $\begin{array}{l}\text { LP, HP, BP, } \\
\text { NF, AP }\end{array}$ & VM & Two & $\begin{array}{c}\text { Two C; Two } \\
\text { R }\end{array}$ & Yes \\
\hline$[14]$ & One & Three & LP, HP, BP & $\mathrm{CM}$ & One & Two C & No \\
\hline$[15]$ & Three & One & $\begin{array}{l}\text { LP, HP, BP, } \\
\text { NF, AP }\end{array}$ & $\mathrm{CM}$ & Two & Two C & Yes \\
\hline$[16]$ & Three & One & $\begin{array}{l}\text { LP, HP, BP, } \\
\text { NF, AP }\end{array}$ & $\mathrm{CM}$ & One & Two C & No \\
\hline [17] & Three & One & $\begin{array}{l}\text { LP, HP, BP, } \\
\text { NF, AP }\end{array}$ & VM & one & Two C & Yes \\
\hline [18] & One & Three & LP, HP, BP & $\mathrm{VM}$ and $\mathrm{CM}$ & One & $\begin{array}{c}\text { Three C; two } \\
\text { R }\end{array}$ & Yes \\
\hline Proposed work & One & Three & LP, HP, BP & $\mathrm{VM}$ and $\mathrm{CM}$ & One & $\begin{array}{c}\text { Three C; one } \\
\text { R }\end{array}$ & Yes \\
\hline
\end{tabular}

presence of nonidealities of VDTA has been analysed in Section 3 and deviation in filter parameters is enumerated. The functionality of the proposed filter has been confirmed through SPICE simulations using $0.18 \mu \mathrm{m}$ TSMC CMOS process parameters and the results are presented in Section 4. Section 5 concludes the paper.

\section{Circuit Description}

The circuit symbol of the VDTA is shown in Figure 1 where $P$ and $N$ are the input terminals and $Z, X_{+}$, and $X_{-}$are the output terminals. The CMOS realization of VDTA [10] is shown in Figure 2. It consists of two transconductance (TC) stages, namely, input and output stages. The input TC stage converts the differential input voltage $\left(V_{P}-V_{N},\right)$ into current $I_{Z}$ through first TC gain $\left(g_{m 1}\right)$ and the voltage at $Z$ terminal $\left(V_{Z}\right)$ is converted to current $\left(I_{X}\right)$ through second TC gain $\left(g_{m 2}\right)$. All VDTA terminals exhibit high impedance values [10]. The port relations are given in matrix form in

$$
\left[\begin{array}{c}
I_{Z} \\
I_{X_{+}} \\
I_{X_{-}}
\end{array}\right]=\left[\begin{array}{ccc}
g_{m 1} & -g_{m 1} & 0 \\
0 & 0 & g_{m 2} \\
0 & 0 & -g_{m 2}
\end{array}\right]\left[\begin{array}{c}
V_{P} \\
V_{N} \\
V_{Z}
\end{array}\right]
$$

The TC gains, $g_{m 1}$ and $g_{m 2}$, respectively, can be expressed as [10]

$$
\begin{aligned}
& g_{m 1}=\frac{g_{1} g_{2}}{g_{1}+g_{2}}+\frac{g_{3} g_{4}}{g_{3}+g_{4}} \\
& g_{m 2}=\frac{g_{5} g_{6}}{g_{5}+g_{6}}+\frac{g_{7} g_{8}}{g_{7}+g_{8}},
\end{aligned}
$$

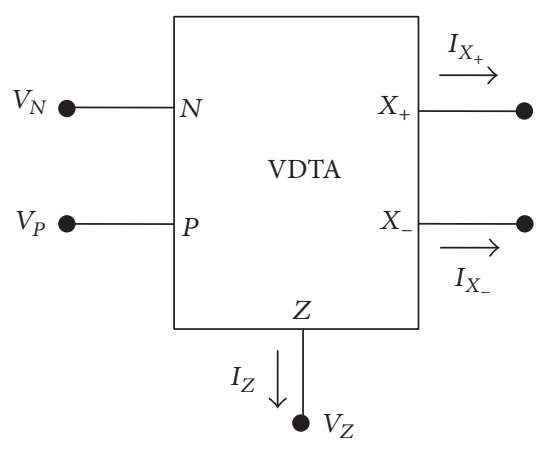

FIgURE 1: Circuit symbol of VDTA.

where $g_{i}$ is the transconductance value of the $i$ th transistor and is given by

$$
g_{i}=\sqrt{\mu C_{\mathrm{ox}}\left(\frac{W}{L}\right)_{i}} I_{B i} .
$$

In (3), $\mu$ is effective carrier mobility; $C_{o x}$ is the gate oxide capacitance per unit area; $I_{B i}$ and $(W / L)_{i}$ represent the dc bias current and the aspect ratio of the $i$ th MOS transistor, respectively.

The proposed dual mode SIMO filter is shown in Figure 3 which comprises of a single VDTA, three capacitors, and a resistor. With appropriate choice of input signal, it can be configured as either VM or CM structure.

2.1. The VM Configuration. The filter configuration of Figure 3 operates in VM if input current is removed $\left(I_{\text {in }}=0\right)$. 


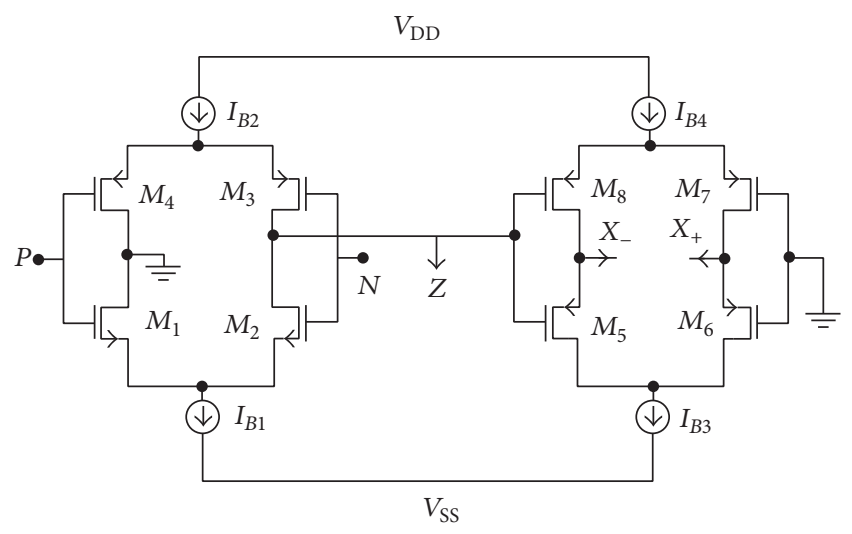

FIgURE 2: The CMOS realization of VDTA [10].

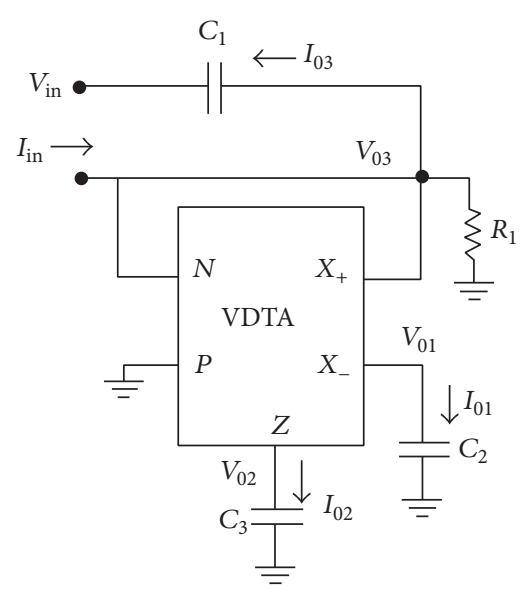

FIGURE 3: Proposed VM and CM mode SIMO filter.

Routine analysis of the circuit yields voltage mode transfer functions given by

$$
\begin{aligned}
& \left.\frac{V_{01}}{V_{\text {in }}}\right|_{\mathrm{LP}}=\frac{g_{m 1} g_{m 2} / C_{2} C_{3}}{\Delta} \\
& \left.\frac{V_{02}}{V_{\text {in }}}\right|_{\mathrm{BP}}=-\frac{\left(g_{m 1} / C_{3}\right) s}{\Delta} \\
& \left.\frac{V_{03}}{V_{\text {in }}}\right|_{\mathrm{HP}}=\frac{s^{2}}{\Delta},
\end{aligned}
$$

where

$$
\Delta=s^{2}+\frac{s}{R_{1} C_{1}}+\frac{g_{m 1} g_{m 2}}{C_{1} C_{3}} .
$$

2.2. The CM Configuration. Removal of voltage source $V_{\text {in }}$ $\left(V_{\text {in }}=0\right)$ in Figure 3 results in CM filter topology. Analysis of the resulting topology leads to the following transfer function:

$$
\begin{aligned}
& \left.\frac{I_{01}}{I_{\text {in }}}\right|_{\mathrm{LP}}=-\frac{g_{m 1} g_{m 2} / C_{1} C_{3}}{\Delta} \\
& \left.\frac{I_{02}}{I_{\text {in }}}\right|_{\mathrm{BP}}=\frac{\left(g_{m 1} / C_{1}\right) s}{\Delta} \\
& \left.\frac{I_{03}}{I_{\text {in }}}\right|_{\mathrm{HP}}=-\frac{s^{2}}{\Delta} .
\end{aligned}
$$

The angular frequency $\omega_{0}$ and quality factor $Q_{0}$ for both the filter structures are given by

$$
\begin{aligned}
\omega_{0} & =\sqrt{\frac{g_{m 1} g_{m 2}}{C_{1} C_{3}}} \\
Q_{0} & =R_{1} \sqrt{\frac{g_{m 1} g_{m 2} C_{1}}{C_{3}}} .
\end{aligned}
$$

It may be observed from (7) and (8) that the parameters $\omega_{0}$ can be set to a desired value and $Q_{0}$ can be controlled through $R_{1}$ independently.

It is relevant to mention here that the voltage outputs of the proposed structure are available at high impedance, which is invariably true for all available VDTA based voltage mode structures $[10,13,17,18]$. It is therefore suggested that either the voltage output structures should be used to drive the high input impedance circuits or the output should be taken through buffers. Further, in CM operation, current outputs are available through passive elements and would require additional $\mathrm{ABBs}$ for accessing current at high impedance. However, it is also applicable to all single ABB based SIMO structures $[12,14,18]$. It may also be noted that in proposed structure $I_{02}$ can be accessed at high impedance by lifting the drain node of transistors $M_{1}$ and $M_{4}$.

The passive sensitivities of $\omega_{0}$ and $Q_{0}$ of the proposed filter structures can be expressed as given by (9) and their absolute values do not exceed unity in magnitude.

$$
\begin{aligned}
S_{g_{m 1}, g_{m 2}}^{\omega_{0}} & =\frac{1}{2}, \\
S_{C_{1}, C_{3}}^{\omega_{0}} & =-\frac{1}{2}, \\
S_{g_{m 1}, g_{m 2}}^{Q_{0}} & =\frac{1}{2}, \\
S_{C_{1}}^{Q_{0}} & =\frac{1}{2}, \\
S_{C_{3}}^{Q_{0}} & =-\frac{1}{2}, \\
S_{R_{1}}^{Q_{0}} & =1 .
\end{aligned}
$$

\section{Nonideal Analysis}

In this section, the effect of nonidealities of VDTA on the filter performance has been analysed. The nonidealities associated 


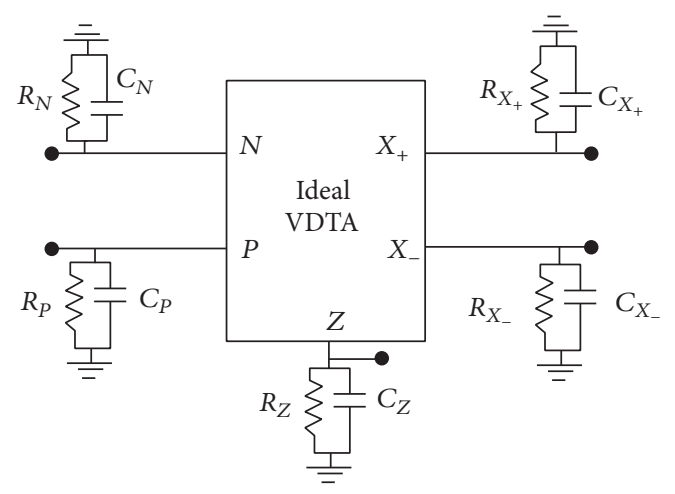

FIGURE 4: Nonideal model of VDTA.

with VDTA based circuits may be divided into two groups. The first group concerns the finite voltage tracking errors and the second results from the presence of parasitics at all the terminals of VDTA.

3.1. Nonideality due to Tracking Error. Taking the tracking errors of the VDTA into account, the port relations expressed by (1) get modified as

$$
\left[\begin{array}{c}
I_{Z} \\
I_{X_{+}} \\
I_{X_{-}}
\end{array}\right]=\left[\begin{array}{ccc}
\beta_{1} g_{m 1} & -\beta_{1} g_{m 1} & 0 \\
0 & 0 & \beta_{2} g_{m 2} \\
0 & 0 & -\beta_{2} g_{m 2}
\end{array}\right]\left[\begin{array}{c}
V_{P} \\
V_{N} \\
V_{Z}
\end{array}\right],
$$

where $\beta_{1}$ and $\beta_{2}$ are, respectively, the tracking errors for the first and second stages of the VDTA. In presence of $\beta_{1}$ and $\beta_{2}$, the new expressions for $\omega_{0}$ and $Q_{0}$ can be obtained as

$$
\begin{aligned}
\omega_{0} & =\sqrt{\frac{\beta_{1} \beta_{2} g_{m 1} g_{m 2}}{C_{1} C_{3}}} \\
Q_{0} & =R_{1} \sqrt{\frac{\beta_{1} \beta_{2} g_{m 1} g_{m 2} C_{1}}{C_{3}}} .
\end{aligned}
$$

It is evident that the values of $\omega_{0}$, and $Q_{0}$ deviate slightly from their ideal values. These changes may be accommodated by adjusting TC gains $g_{m 1}$ and $g_{m 2}$ through bias current of VDTA. However, the sensitivities of $\omega_{0}$ and $Q_{0}$ with respect to $\beta_{1}$ and $\beta_{2}$ are quite low, as given by

$$
S_{\beta_{1}, \beta_{2}}^{\omega_{0}}=S_{\beta_{1}, \beta_{2}}^{Q_{0}}=\frac{1}{2} \text {. }
$$

3.2. Nonideality due to Parasitics. The nonideal model of VDTA is shown in Figure 4 wherein each terminal is characterized by finite parasitic impedance consisting of resistance in parallel with capacitance $\left(R_{P}, C_{P} ; R_{N}, C_{N} ; R_{Z}, C_{Z}\right.$; $R_{X_{+}}, C_{X_{+}} ; R_{X_{-}}, C_{X_{-}}$for $V_{P}, V_{N}, Z$, and $X$ terminals, resp.) [12]. The filter performance might deviate from ideal behaviour due to parasitics of VDTA. Thus, the filter structure of Figure 3 is to be analysed in the presence of parasitics. Using the nonideal model of VDTA, the proposed filter structure can be redrawn as shown in Figure 5.

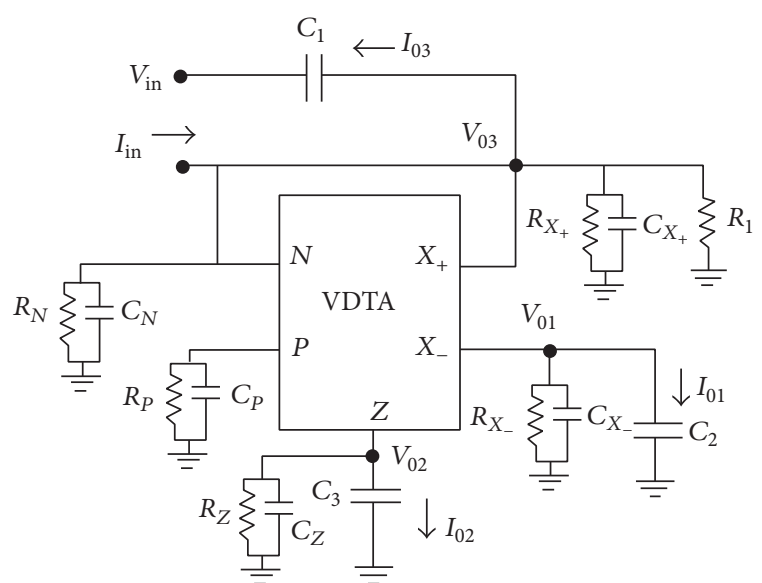

FIGURE 5: Nonideal filter structure.

Using routine analysis, $\omega_{0}$ and $Q_{0}$ of the filter configuration of Figure 5 may be obtained as

$$
\begin{aligned}
& \omega_{0}=\sqrt{\frac{A}{B}} \\
& Q_{0}=\sqrt{\frac{A B}{D}},
\end{aligned}
$$

where

$$
\begin{aligned}
A= & g_{m 1} g_{m 2}+\frac{1}{R_{1} R_{Z}}+\frac{1}{R_{X_{+}} R_{Z}}+\frac{1}{R_{N} R_{Z}} \\
B= & C_{1} C_{3}+C_{Z} C_{3}+C_{X_{+}} C_{Z}+C_{N} C_{Z}+C_{2} C_{X_{+}} \\
& +C_{2} C_{N}, \\
D= & \left(\frac{C_{3}}{R_{Z}}+\frac{C_{3}}{R_{1}}+\frac{C_{2}}{R_{X_{+}}}+\frac{C_{Z}}{R_{1}}+\frac{C_{Z}}{R_{X_{+}}}+\frac{C_{Z}}{R_{N}}+\frac{C_{X_{+}}}{R_{Z}}\right. \\
& \left.+\frac{C_{N}}{R_{Z}}\right)^{2} .
\end{aligned}
$$

The parasitic resistances associated with all terminals are practically too large making

$$
\left(\frac{1}{R_{1} R_{Z}}+\frac{1}{R_{X_{+}} R_{Z}}+\frac{1}{R_{N} R_{Z}}\right)\left\langle\left\langle g_{m 1} g_{m 2} .\right.\right.
$$

Thus, (15) reduces to

$$
A \approx g_{m 1} g_{m 2} .
$$

By selecting external capacitances much larger than parasitic capacitances, (16) can be simplified as

$$
\begin{aligned}
B= & C_{3} C_{1}+C_{Z}\left(C_{3}+C_{X_{+}}\right)+C_{X_{+}}\left(C_{2}+C_{Z}\right) \\
& +C_{2} C_{N}=C_{3} C_{1}+C_{Z} C_{3}+C_{X_{+}} C_{2}+C_{2} C_{N} \\
= & C_{3}\left(C_{1}+C_{Z}\right)+C_{2}\left(C_{X_{+}}+C_{Z}\right) \approx C_{3} C_{1} .
\end{aligned}
$$


TABLE 2: List of $0.18 \mu \mathrm{m}$ CMOS process parameters used.

LEVEL $=7+$ VERSION $=3.1$ TNOM $=27$ TOX $=4.1 \mathrm{E}-9+\mathrm{XJ}=1 \mathrm{E}-7 \mathrm{NCH}=2.3549 \mathrm{E} 17$

$\mathrm{VTHO}=0.3672292+\mathrm{K} 1=0.5893162 \mathrm{~K} 2=3.053194 \mathrm{E}-3 \mathrm{~K} 3=1 \mathrm{E}-3+\mathrm{K} 3 \mathrm{~B}=1.8246765$

$\mathrm{WO}=1 \mathrm{E}-7 \mathrm{NLX}=1.771394 \mathrm{E}-7+\mathrm{DVTOW}=0 \mathrm{DVT} 1 \mathrm{~W}=0 \mathrm{DVT} 2 \mathrm{~W}=0+\mathrm{DVT} 0=1.2540673$ DVT $1=$

$0.3671218 \mathrm{DVT} 2=0.0374285+\mathrm{UO}=2.3448599 \mathrm{UA}=-1.473692 \mathrm{E}-9 \mathrm{UB}=2.452512 \mathrm{E}-18+\mathrm{UC}=$

$6.566514 \mathrm{E}-11 \mathrm{VSAT}=1.025312 \mathrm{E} 5 \mathrm{AO}=2+\mathrm{AGS}=0.4532362 \mathrm{BO}=3.222688 \mathrm{E}-7 \mathrm{~B} 1=5 \mathrm{E}-6+\mathrm{KETA}$

$=-0.0109204 \mathrm{~A} 1=0 \mathrm{~A} 2=0.9744209+\mathrm{RDSW}=105 \mathrm{PRWG}=5 \mathrm{PRWB}=-0.2+\mathrm{WR}=1 \mathrm{WINT}=$

$1.660932 \mathrm{E}-9$ LINT $=.520122 \mathrm{E}-8+\mathrm{XL}=0 \mathrm{XW}=-1 \mathrm{E}-8 \mathrm{DWG}=-2.794177 \mathrm{E}-9+\mathrm{DWB}=7.839758 \mathrm{E}-9$

$\mathrm{VOFF}=-0.091184 \mathrm{NFACTOR}=2.2684002+\mathrm{CIT}=0 \mathrm{CDSC}=2.4 \mathrm{E}-4 \mathrm{CDSCD}=$

$0+\mathrm{CDSCB}=0 \mathrm{ETAO}=3.031184 \mathrm{E}-3 \mathrm{ETAB}=9.427488 \mathrm{E}-6+\mathrm{DSUB}=0.0153239$ PCLM $=0.704686$

NMOS PDIBLC1 $=2435533+\mathrm{PDIBLC} 2=2.76003 \mathrm{E}-3$ PDIBLCB $=-0.1$ DROUT $=0.8035265+\mathrm{PSCBE} 1=$ $4.372065 \mathrm{E} 10$ PSCBE2 $=2.518414 \mathrm{E}-9$ PVAG $=0.0749313+\mathrm{DELTA}=0.01 \mathrm{RSH}=6.4$ MOBMOD $=$ $1+\mathrm{PRT}=0 \mathrm{UTE}=-1.5 \mathrm{KT} 1=-0.11+\mathrm{KT} 1 \mathrm{~L}=0 \mathrm{KT} 2=0.022 \mathrm{UA} 1=4.31 \mathrm{E}-9+\mathrm{UB} 1=-7.61 \mathrm{E}-18$ $\mathrm{UC1}=-5.6 \mathrm{E}-11 \mathrm{AT}=3.3 \mathrm{E} 4+\mathrm{WL}=0 \mathrm{WLN}=1 \mathrm{WW}=0+\mathrm{WWN}=1 \mathrm{WWL}=0 \mathrm{LL}=0+\mathrm{LLN}=1 \mathrm{LW}=$ $0 \mathrm{LWN}=1+\mathrm{LWL}=0 \mathrm{CAPMOD}=2 \mathrm{XPART}=0.5+\mathrm{CGDO}=8.79 \mathrm{E}-10 \mathrm{CGSO}=8.79 \mathrm{E}-10 \mathrm{CGBO}=$ $1 \mathrm{E}-12+\mathrm{CJ}=9.605878 \mathrm{E}-4 \mathrm{~PB}=0.8 \mathrm{MJ}=0.3831903+\mathrm{CJSW}=.643918 \mathrm{E}-10 \mathrm{PBSW}=0.8 \mathrm{MJSW}=$ $0.1407086+\mathrm{CJSWG}=3.3 \mathrm{E}-10 \mathrm{PBSWG}=0.8 \mathrm{MJSWG}=0.1407086+\mathrm{CF}=0 \mathrm{PVTHO}=-6.317463 \mathrm{E}-6$ PRDSW $=-.8440536+\mathrm{PK} 2=9.250773 \mathrm{E}-4$ WKETA $=1.074587 \mathrm{E}-3$ LKETA $=-.453047 \mathrm{E}-3+\mathrm{PUO}=$ $4.3638022 \mathrm{PUA}=-1.50117 \mathrm{E}-12 \mathrm{PUB}=0+\mathrm{PVSAT}=1.356677 \mathrm{E} 3$ PETAO $=1.003159 \mathrm{E}-4$ PKETA $=-2.902589 \mathrm{E}-3$

LEVEL $=7+$ VERSION $=3.1$ TNOM $=27$ TOX $=4.1 \mathrm{E}-9+\mathrm{XJ}=1 \mathrm{E}-7 \mathrm{NCH}=4.1589 \mathrm{E} 17$ VTHO $=$ $-0.38888+\mathrm{K} 1=0.5636481 \mathrm{~K} 2=0.0308017 \mathrm{~K} 3=0+\mathrm{K} 3 \mathrm{~B}=7.400372$ w0 $=1 \mathrm{E}-6 \mathrm{NLX}=$ $1.385693 \mathrm{E}-7+\mathrm{DVTOW}=$ ODVT1W $=0$ DVT2 $\mathrm{W}=0+\mathrm{DVTO}=0.5846878$ DVT1 $=0.2165736$ DVT2 $=$ $0.1+\mathrm{UO}=3.6325808 \mathrm{UA}=1.459877 \mathrm{E}-9 \mathrm{UB}=1.18636 \mathrm{E}-21+\mathrm{UC}=-1 \mathrm{E}-10$ VSAT $=2 \mathrm{E} 5$ $\mathrm{AO}=1.7849198+\mathrm{AGS}=0.3754547 \mathrm{BO}=3.172437 \mathrm{E}-7 \mathrm{~B} 1=7.280105 \mathrm{E}-7+\mathrm{KETA}=0.0156934$ $\mathrm{A} 1=0.3222966 \mathrm{~A} 2=0.3+\mathrm{RDSW}=196.7345438 \mathrm{PRWG}=0.5 \mathrm{PRWB}=-0.1589203+\mathrm{WR}=1$ WINT $=0$ LINT $=2.702835 \mathrm{E}-8+\mathrm{XL}=0 \mathrm{XW}=-1 \mathrm{E}-8 \mathrm{DWG}=-2.627805 \mathrm{E}-8+\mathrm{DWB}=1.03876 \mathrm{E}-9$ $\mathrm{VOFF}=-0.0927458 \mathrm{NFACTOR}=2+\mathrm{CIT}=0 \mathrm{CDSC}=2.4 \mathrm{E}-4 \mathrm{CDSCD}=0+\mathrm{CDSCB}=0$ ETAO $=0.145648 \mathrm{ETAB}=-0.0543017+\mathrm{DSUB}=0.9610783$ PCLM $=2.0812378$ PDIBLC1 $=$

PMOS $7.131255 \mathrm{E}-4+\mathrm{PDIBLC} 2=0.0185628 \mathrm{PDIBLCB}=-9.170788 \mathrm{E}-4$ DROUT $=0+\mathrm{PSCBE} 1=3.206374 \mathrm{E} 9$ PSCBE2 $=9.279285 \mathrm{E}-10 \mathrm{PVAG}=15+\mathrm{DELTA}=0.01 \mathrm{RSH}=7.3 \mathrm{MOBMOD}=1+\mathrm{PRT}=0 \mathrm{UTE}=-1.5$ $\mathrm{KT} 1=-0.11+\mathrm{KT} 1 \mathrm{~L}=0 \mathrm{KT} 2=0.022 \mathrm{UA} 1=.31 \mathrm{E}-9+\mathrm{UB} 1=-7.61 \mathrm{E}-18 \mathrm{UC} 1=-5.6 \mathrm{E}-11$ $\mathrm{AT}=3.3 \mathrm{E} 4+\mathrm{WL}=0 \mathrm{WLN}=1 \mathrm{WW}=0+\mathrm{WWN}=1 \mathrm{WWL}=0 \mathrm{LL}=0+\mathrm{LLN}=1 \mathrm{LW}=0 \mathrm{LWN}=1+\mathrm{LWL}=0$ CAPMOD $=2$ XPART $=0.5+$ CGDO $=6.41 \mathrm{E}-10 \mathrm{CGSO}=6.41 \mathrm{E}-10 \mathrm{CGBO}=1 \mathrm{E}-12+\mathrm{CJ}=1.136354 \mathrm{E}-3$ $\mathrm{PB}=0.8459606 \mathrm{MJ}=0.4088875+\mathrm{CJSW}=2.255183 \mathrm{E}-10 \mathrm{PBSW}=0.832695 \mathrm{MJSW}=$ $0.3342249+\mathrm{CJSWG}=4.22 \mathrm{E}-10 \mathrm{PBSWG}=0.832695 \mathrm{MJSWG}=0.3342249+\mathrm{CF}=0$ PVTHO $=$ $4.532819 \mathrm{E}-3$ PRDSW $=7.6587079+\mathrm{PK} 2=3.513392 \mathrm{E}-3$ WKETA $=0.0251295$ LKETA $=$ $-2.32504 \mathrm{E}-3+\mathrm{PUO}=-.4738884 \mathrm{PUA}=-8.40745 \mathrm{E}-11 \mathrm{PUB}=1 \mathrm{E}-21+\mathrm{PVSAT}=-50 \mathrm{PETAO}=1 \mathrm{E}-4$ PKETA $=-2.114056 \mathrm{E}-3$

Similarly, (17) can be simplified as

$$
\begin{aligned}
D & =\left(\frac{C_{3}}{R_{Z}}+\frac{C_{3}}{R_{1}}+\frac{C_{2}}{R_{X_{+}}}+\frac{C_{Z}}{R_{1}}+\frac{C_{Z}}{R_{X_{+}}}+\frac{C_{Z}}{R_{N}}+\frac{C_{X_{+}}}{R_{Z}}\right. \\
& \left.+\frac{C_{N}}{R_{Z}}\right)^{2}=\left(\frac{C_{3}+C_{Z}+C_{N}}{R_{1}}+\frac{C_{3}+C_{X_{+}}}{R_{Z}}\right. \\
& \left.+\frac{C_{Z}+C_{2}}{R_{X_{+}}}+\frac{C_{Z}}{R_{N}}\right)^{2} \approx\left(\frac{C_{3}}{R_{1}}+\frac{C_{3}}{R_{Z}}+\frac{C_{2}}{R_{X_{+}}}\right. \\
& \left.+\frac{C_{Z}}{R_{N}}\right)^{2} \approx\left(\frac{C_{3}}{R_{1}}+\frac{C_{3}}{R_{Z}}+\frac{C_{2}}{R_{X_{+}}}\right)^{2} \approx\left(\frac{C_{3}}{R_{1}}\right)^{2} .
\end{aligned}
$$

Substituting (19) and (20), it may thus be noted that (13) can be approximated to (7) which represents the ideal value of $\omega_{0}$.
Also putting (19), (20), and (21) in (14), $Q_{0}$ may be expressed by (22) which is equal to its ideal value.

$$
Q_{0} \approx \sqrt{\frac{g_{m 1} g_{m 2} C_{3} C_{1}}{\left(C_{3} / R_{1}\right)^{2}}}=R_{1} \sqrt{\frac{g_{m 1} g_{m 2} C_{1}}{C_{3}}} .
$$

It may be concluded therefore that, by selecting external capacitances much larger than parasitic capacitances, the frequency response of the proposed structure would not be affected.

\section{Simulation Results}

The functionality of the proposed filter is validated through SPICE simulated using $0.18 \mu \mathrm{m}$ TSMC process parameters which have been listed in Table 2 for ready reference. First, the DC transfer characteristic of the VDTA is validated which is followed by verification of both VM and CM filter responses. 


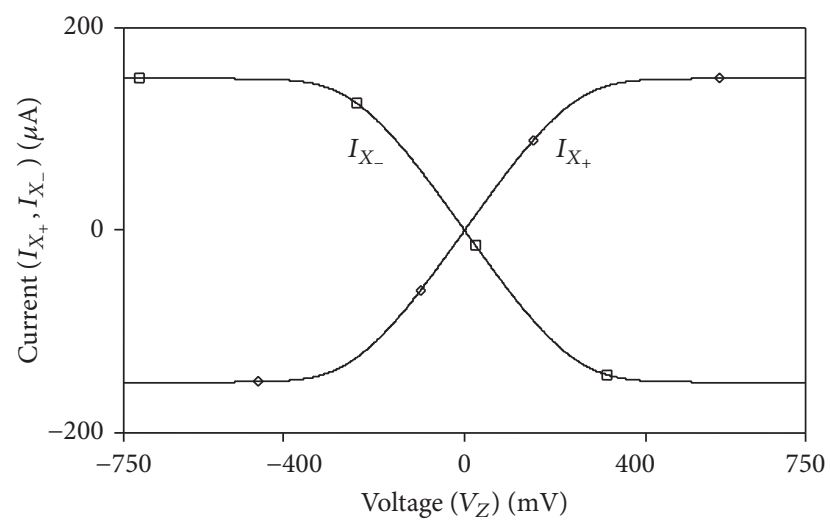

Figure 6: The DC transfer characteristics of the VDTA.

Subsequently, as a case study, the transient behaviour of $\mathrm{BP}$ filter (VM and CM) is studied and its total harmonic distortion (THD) variation is also observed.

4.1. The DC Transfer Characteristic. The VDTA structure shown in Figure 3 [10] with supply voltages of $\pm 0.9 \mathrm{~V}$ is used for simulation. The same aspect ratios of the MOS transistors are used as given in [10]. The DC transfer characteristic of the VDTA, as shown in Figure 6, is plotted for $I_{B 1}=I_{B 2}=I_{B 3}=$ $I_{B 4} \cong 150 \mu \mathrm{A}$, which resulted in $g_{m 1}=g_{m 2}=636.3 \mu \mathrm{A} / \mathrm{V}$.

4.2. Frequency Response. The LP, HP, and BP filter responses for both VM and CM filter structures with $f_{0}=1 \mathrm{MHz}$ and $Q_{0}=1$ are shown in Figures 7(a) and 7(b), respectively. The passive components were chosen as $C_{1}=C_{2}=C_{3}=0.1 \mathrm{nF}$ and $R_{1}=1.57 \mathrm{~K} \Omega$. The tuning of gain expression for low pass filter with respect to $C_{2}$ is shown in Figure 7(c).

It may be observed from (7) and (8) that $f_{0}$ can be tuned by changing either capacitance values $\left(C_{1}, C_{3}\right)$ or the transconductances $\left(g_{m 1}, g_{m 2}\right)$. The transconductance variation can be obtained through bias current adjustment. The $Q_{0}$ tuning can be accomplished through $R_{1}$ without affecting $f_{0}$. The orthogonal adjustment of $f_{0}$ and $Q_{0}$ is shown by plotting the $\mathrm{BP}$ responses for $f_{0}=100 \mathrm{KHz}, 1 \mathrm{MHz}$, and $10 \mathrm{MHz}$ while keeping $Q_{0}$ fixed at 1 . The responses for VM and CM structures are shown in Figures 8(a) and 8(b), respectively. Similarly, the simulation results for $Q_{0}=0.5,1$, and 5 when $f_{0}$ remains constant at $1 \mathrm{MHz}$, for $\mathrm{VM}$ and $\mathrm{CM}$ topologies, are shown in Figures 9(a) and 9(b), respectively. It is evident from Figures 8 and 9 that $f_{0}$ and $Q_{0}$ are orthogonally tunable.

Another set of simulations have been carried out to examine frequency response limitations of the proposed structure. Low pass current mode response is used for illustration. The simulations conditions on bias currents are kept the same as reported in the beginning while the capacitor values are changed and corresponding theoretical and simulated pole frequencies are noted and listed in Table 3. It may be noted that there is a close match between theoretical and simulated pole frequencies when the values of external capacitors are chosen to be sufficiently greater than parasitic capacitances. However, a significant deviation is seen when
TABLE 3: The \% frequency deviation for CM LP filter.

\begin{tabular}{lccc}
\hline $\begin{array}{l}\text { Capacitor } \\
\text { value }\end{array}$ & Theoretical $f_{0}$ & Simulated $f_{0}$ & $\begin{array}{c}\text { \% frequency } \\
\text { deviation }\end{array}$ \\
\hline $0.1 \mathrm{nF}$ & $1.01231 \mathrm{MHz}$ & $1.06 \mathrm{MHz}$ & 4.5 \\
$0.01 \mathrm{nF}$ & $10.1231 \mathrm{MHz}$ & $10.639 \mathrm{MHz}$ & 4.8 \\
$1 \mathrm{pF}$ & $101.231 \mathrm{MHz}$ & $108.854 \mathrm{MHz}$ & 7.0 \\
$0.1 \mathrm{pF}$ & $1.01231 \mathrm{GHz}$ & $886.833 \mathrm{MHz}$ & 12.3 \\
$0.01 \mathrm{pF}$ & $10.1231 \mathrm{GHz}$ & $2.269 \mathrm{GHz}$ & 77.0 \\
$1 \mathrm{fF}$ & $101.231 \mathrm{GHz}$ & $2.76 \mathrm{GHz}$ & 97.3 \\
\hline
\end{tabular}

external capacitances are selected close to parasitics (tens of $\mathrm{fF}$ order). Further, it is also observed that parasites limit frequency range because their pole frequencies are much lower than those for tracking errors.

4.3. Transient Response. The time domain behaviour of the VM BP filter is also studied by applying three sinusoidal frequency components: a low frequency signal of $1 \mathrm{MHz}$, a high frequency component of $100 \mathrm{MHz}$, and the third component of $10 \mathrm{MHz}$ which is $f_{0}$ of the BP filter. The input signal is shown in Figure 10(a) and its frequency spectrum is depicted in Figure 10(b). The transient response of the filter and the associated frequency spectrum are shown in Figures 11(a) and 11(b), respectively. It may be noted that the frequency components other than $f_{0}$ are significantly attenuated.

To observe the transient response of CM BP filter, it is driven by an input current signal consisting of three frequency components: $1 \mathrm{KHz}, 10 \mathrm{KHz}$, and $100 \mathrm{KHz}$. The $\mathrm{BP}$ filter is designed for an $f_{0}=10 \mathrm{KHz}$. The related results are depicted in Figures 12 and 13 which clearly show that the signals outside the bandwidth of BP filter are significantly attenuated.

To check the quality of the output of BP filter, the percentage total harmonic distortion (\%THD) with the sinusoidal input signal is obtained as shown in Figure 14. It is observed from Figure 14(a) that the \% THD remains considerably low [19] for input signal values up to $500 \mathrm{mV}$ for VM topology. Similarly, it may be noted from Figure 14(b) that the \%THD is well below $7 \%$ for current signals up to $200 \mu \mathrm{A}$. The simulated value of power dissipation, in both $\mathrm{VM}$ and $\mathrm{CM}$ operations, is observed to be $0.54 \mathrm{~mW}$.

\section{Conclusion}

A single VDTA based dual mode SIMO biquad which realizes $\mathrm{LP}, \mathrm{HP}$, and BP responses has been proposed in this paper. The proposed biquad is a SIMO structure and can be configured as voltage mode or current mode with appropriate input excitation selection. The angular frequency and the quality factor of the proposed configuration can be controlled in a noninteractive manner. The filter $f_{0}$ is electronically tunable. The filter structure functionality is verified through SPICE 

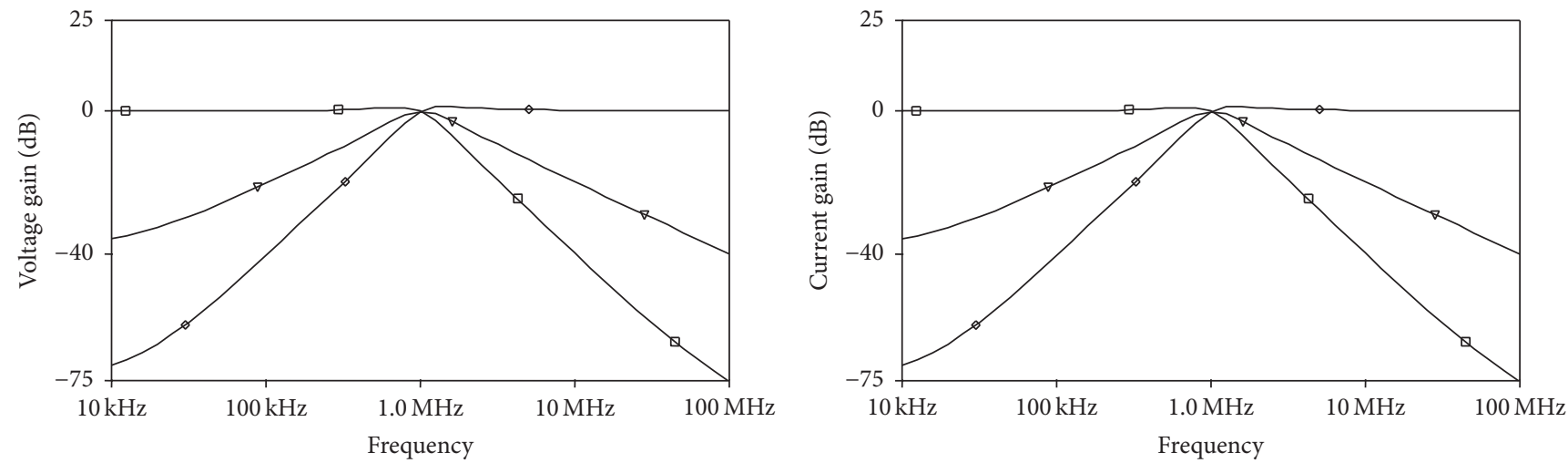

$\diamond C_{2}=0.01 \mathrm{nF}$

$\nabla C_{2}=0.1 \mathrm{nF}$

$\mathrm{C}_{2}=0.01 \mathrm{nF}$

口 $C_{2}=1 \mathrm{nF}$

$\nabla C_{2}=0.1 \mathrm{nF}$

口 $C_{2}=1 \mathrm{nF}$

(a)

(b)

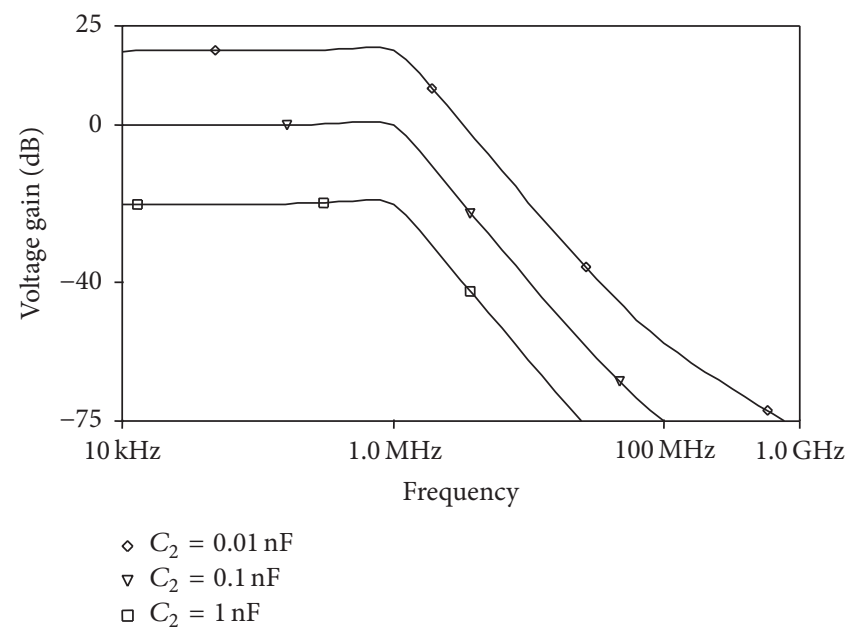

(c)

FIGURE 7: Frequency response at $f_{0}=1 \mathrm{MHz}$ and $Q_{0}=1$. (a) VM topology. (b) CM topology. (c) VM LP filter depicting gain tuning with $C_{2}$.
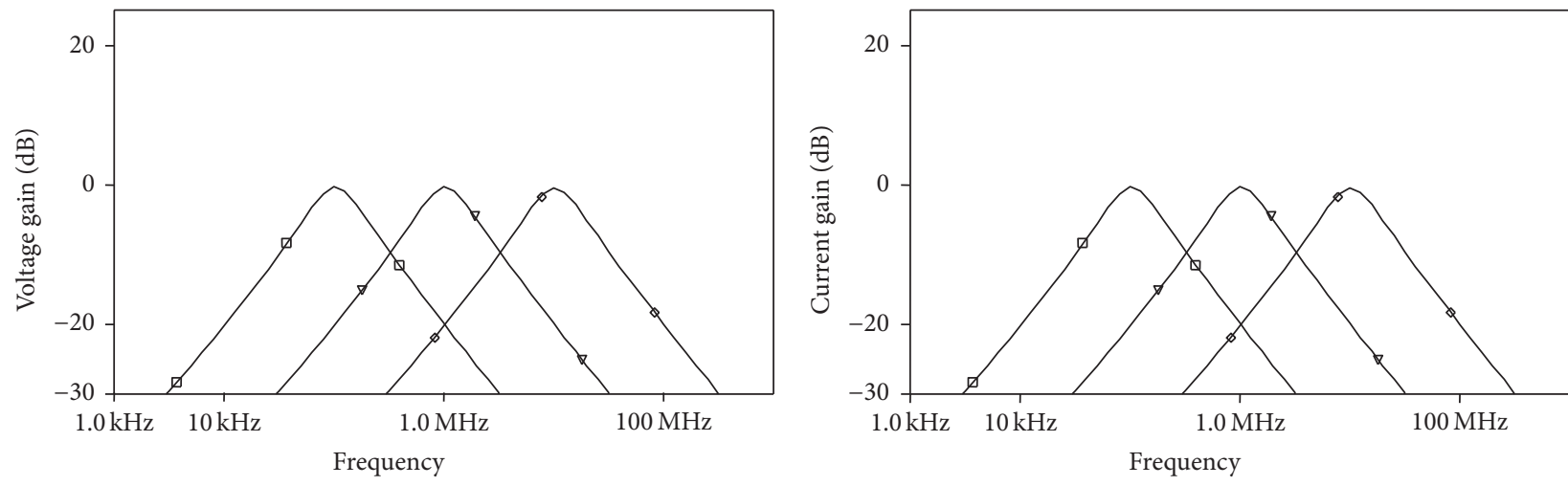

- $f=100 \mathrm{kHz}$
$f=1 \mathrm{MHz}$
$\checkmark f=10 \mathrm{MHz}$

○ $f=100 \mathrm{kHz}$

$f=1 \mathrm{MHz}$

$\nabla f=10 \mathrm{MHz}$

(a)

(b)

Figure 8: BP responses for $f_{0}=100 \mathrm{KHz}, 1 \mathrm{MHz}$, and $10 \mathrm{MHz}$ keeping $Q_{0}$ fixed at 1 for (a) VM and (b) CM topology. 

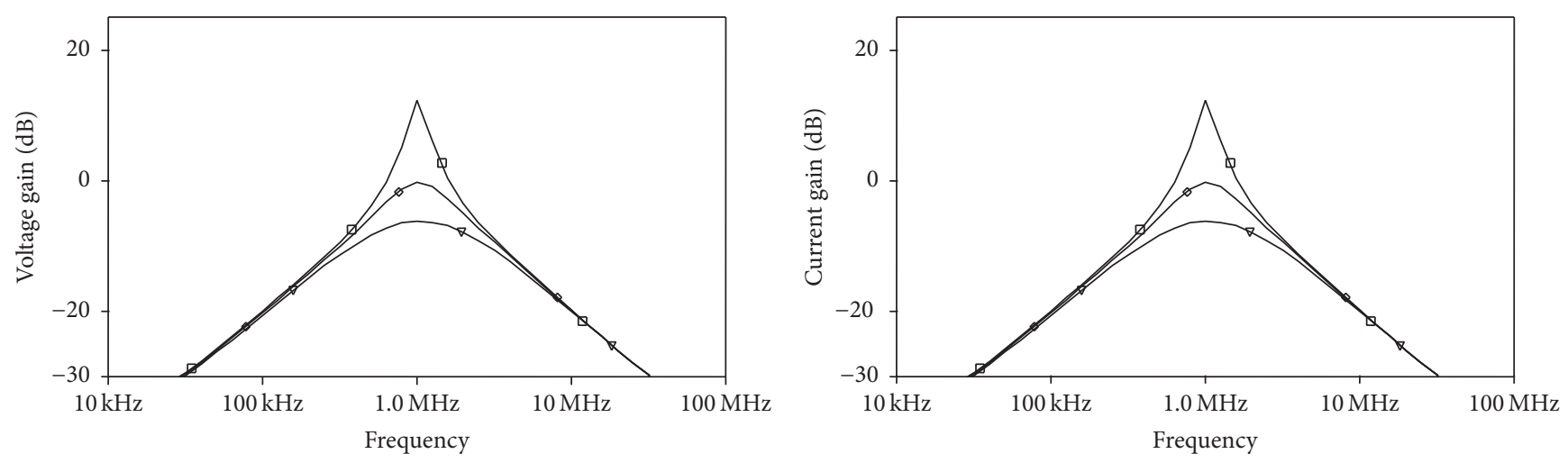

$=5$
$\therefore Q=1$
$\nabla Q=0.5$

ㅁ $\mathrm{Q}=5$

○ $Q=1$

$\nabla \mathrm{Q}=0.5$

(a)

(b)

FIGURE 9: BP responses for $Q_{0}=0.5,1$, and 5 with $f_{0}=1 \mathrm{MHz}$ for (a) VM and (b) CM topology.

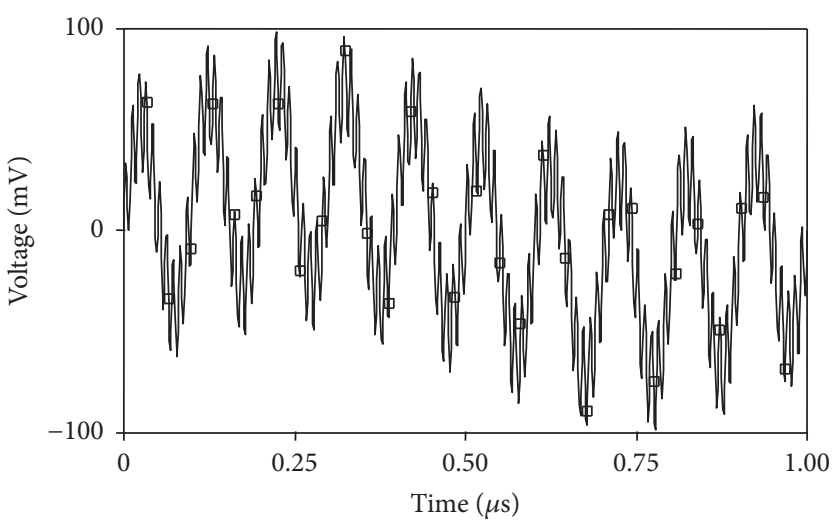

(a)

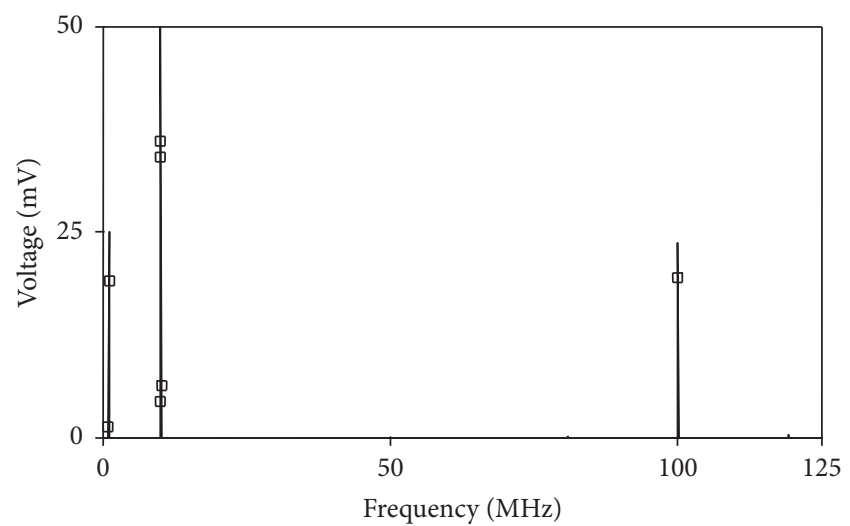

(b)

FIGURE 10: (a) The voltage input transient signal and (b) its frequency spectrum.

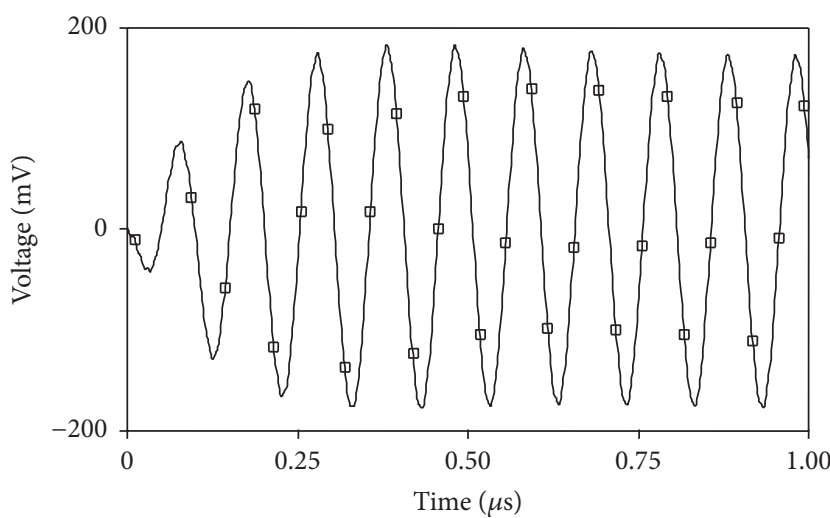

(a)

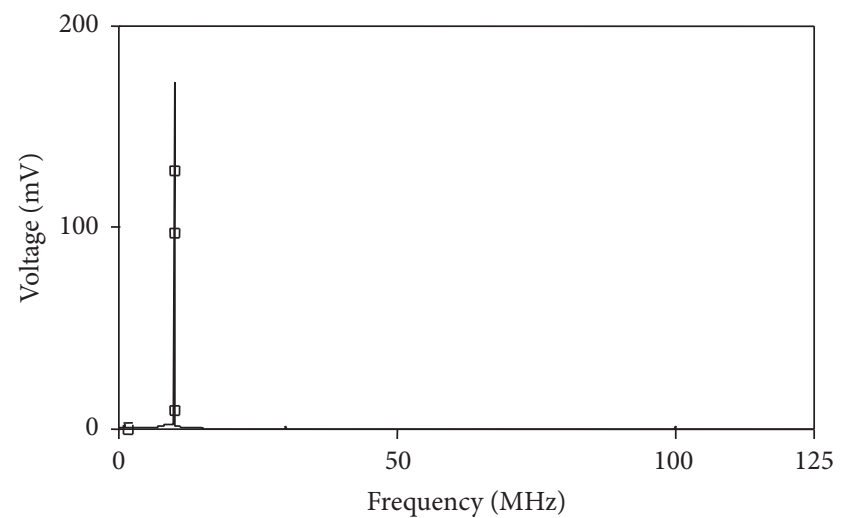

(b)

FIGURE 11: (a) The voltage output transient signal and (b) its frequency spectrum. 


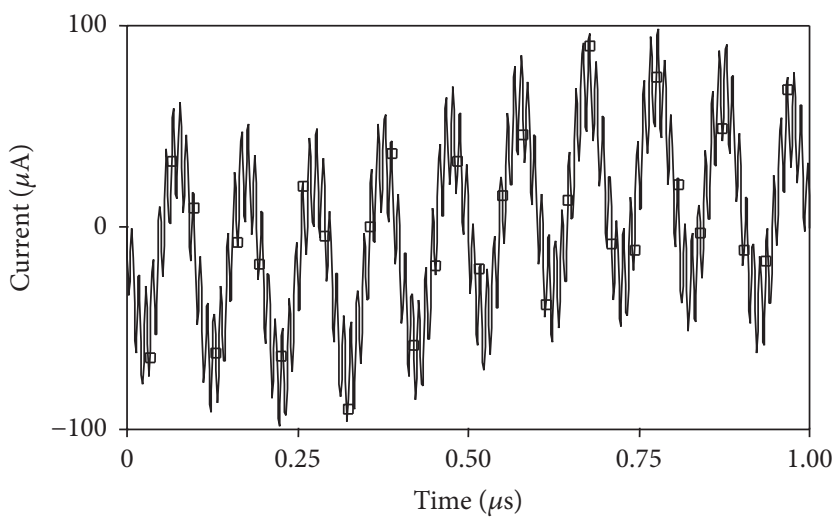

(a)

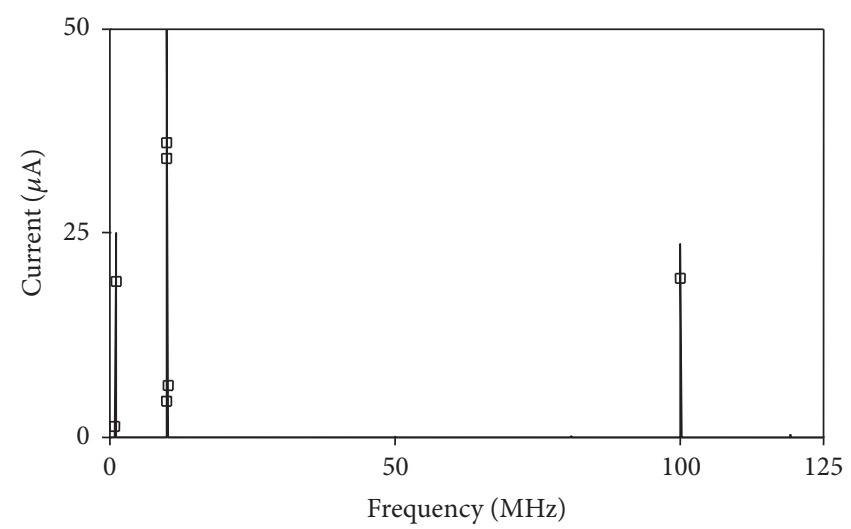

(b)

FIGURE 12: (a) The current input transient signal and (b) its frequency spectrum.

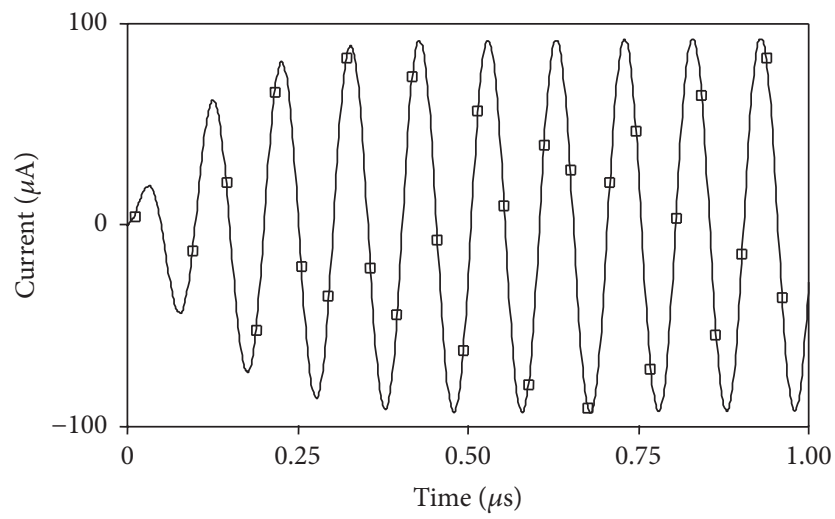

(a)

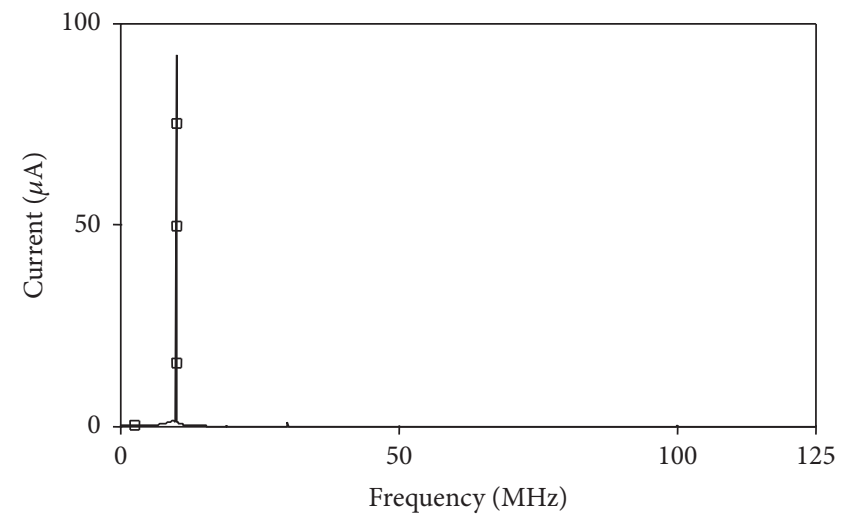

(b)

FIGURE 13: (a) The current output transient signal and (b) its frequency spectrum.

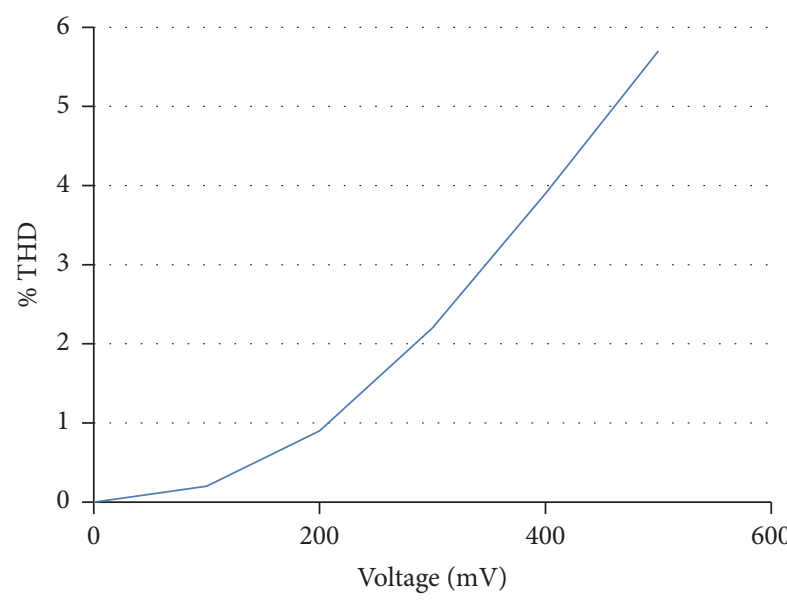

— $\%$ THD

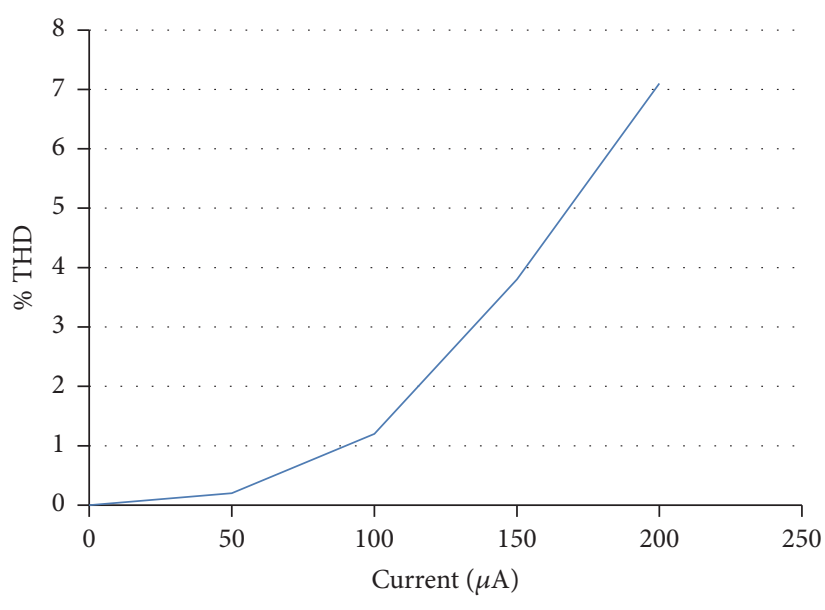

— $\%$ THD

(a)

(b)

FIGURE 14: THD variation of BP filter against amplitude of the applied sinusoidal signal at $159 \mathrm{KHz}$ (a) voltage mode and (b) current mode. 
simulations and both frequency and transient responses are studied.

\section{Competing Interests}

The authors declare that they have no competing interests.

\section{References}

[1] C. Toumazau, F. J. Lidgey, and D. G. Haigh, Analogue IC Design: The Current-mode Approach, Peter Peregrinus Limited, London, UK, 1990.

[2] D. Biolek, R. Senani, V. Biolkova, and Z. Kolka, "Active elements for analog signal processing: classification, review, and new proposals," Radioengineering, vol. 17, no. 4, pp. 15-32, 2008.

[3] N. Pandey and S. K. Paul, "Differential difference current conveyor transconductance amplifier: a new analog building block for signal processing," Journal of Electrical and Computer Engineering, vol. 2011, Article ID 361384, 10 pages, 2011.

[4] D. Biolek, "CDTA-building block for current-mode analog signal processing," in Proceedings of the European Conference on Circuit Theory and Design (ECCTD '03), vol. 3, pp. 397-400, 2003.

[5] W. Tangsrirat and W. Surakampontorn, "Single-resistancecontrolled quadrature oscillator and universal biquad filter using CFOAs," AEU-International Journal of Electronics and Communications, vol. 63, no. 12, pp. 1080-1086, 2009.

[6] R. Pandey, N. Pandey, S. K. Paul, A. Singh, B. Sriram, and K. Trivedi, "Novel grounded inductance simulator using single OTRA," International Journal of Circuit Theory and Applications, vol. 42, no. 10, pp. 1069-1079, 2014.

[7] N. Herencsár, J. Koton, K. Vrba, and I. Lattenberg, "New voltage-mode universal filter and sinusoidal oscillator using only single DBTA," International Journal of Electronics, vol. 97, no. 4, pp. 365-379, 2010.

[8] R. Pandey, N. Pandey, T. Negi, and V. Garg, "CDBA based universal inverse filter," ISRN Electronics, vol. 2013, Article ID 181869, 6 pages, 2013.

[9] N. Herencsar, J. Koton, and K. Vrba, "Single CCTA-based universal biquadratic filters employing minimum components," International Journal of Electrical and Computer Engineering, vol. 1, no. 3, pp. 316-319, 2009.

[10] D. Biolek, M. Shaktour, V. Biolkova, and Z. Kolka, "Currentinput current-output universal biquad employing two bulkdriven VDTAs," in Proceedings of the 4th International Congress on Ultra Modern Telecommunications and Control Systems (ICUMT '12), pp. 484-489, IEEE, St. Petersburg, Russia, October 2012.

[11] A. Yeşil, F. Kaçar, and H. Kuntman, "New simple CMOS realization of voltage differencing transconductance amplifier and its RF filter application," Radioengineering, vol. 20, no. 3, pp. 632-637, 2011.

[12] D. Prasad, D. R. Bhaskar, and M. Srivastava, "Universal currentmode biquad filter using a VDTA," Circuits and Systems, vol. 4, pp. 29-33, 2013.

[13] J. Satansup, T. Pukkalanun, and W. Tangsrirat, "Electronically tunable single-input five-output voltage-mode universal filter using VDTAs and grounded passive elements," Circuits, Systems, and Signal Processing, vol. 32, no. 3, pp. 945-957, 2013.

[14] J. Satansup and W. Tangsrirat, "Single VDTA-based currentmode electronically tunable multifunction filter," in Proceedings of the 4th International Science, Social Science, Engineering and Energy Conference, pp. 1-8, 2012.

[15] J. Satansup, T. Pukkalanun, and W. Tangsrirat, "Electronically tunable current-mode universal filter using VDTAs and grounded capacitors," in Proceedings of the International Multiconference of Engineers and Computer Scientists, vol. 2, pp. 647650, 2013.

[16] J. Satansup and W. Tangsrirat, "Compact VDTA-based currentmode electronically tunable universal filters using grounded capacitors," Microelectronics Journal, vol. 45, no. 6, pp. 613-618, 2014.

[17] J. Satansup and W. Tangsrirat, "VDTA based voltage-mode electronically tunable universal filter," in Proceedings of the 27th International Technical Conference on Circuits/Systems, Computers and Communications, pp. 1-4, July 2012.

[18] N. Singhal, R. Pandey, and N. Pandey, "Dual mode biquadratic filter using single VDTA," International Journal of Electrical and Electronics Engineers, vol. 6, pp. 134-139, 2014.

[19] E. S. Erdogan, R. O. Topaloglu, H. Kuntman, and O. Cicekoglu, "New current-mode special function continuous-time active filters employing only OTAs and OPAMPs," International Journal of Electronics, vol. 91, no. 6, pp. 345-359, 2004. 


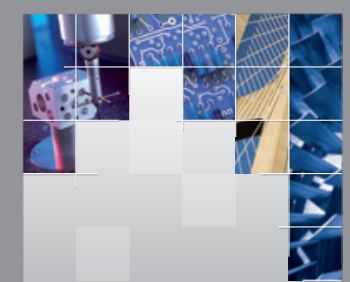

\section{Enfincering}
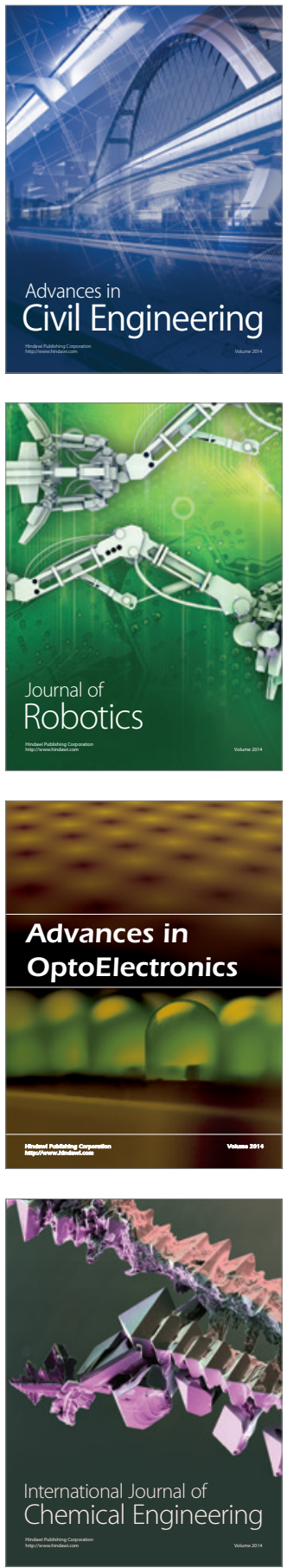

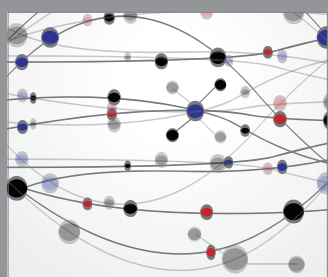

The Scientific World Journal

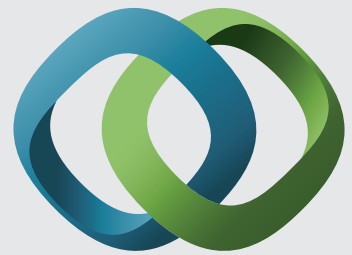

\section{Hindawi}

Submit your manuscripts at

http://www.hindawi.com
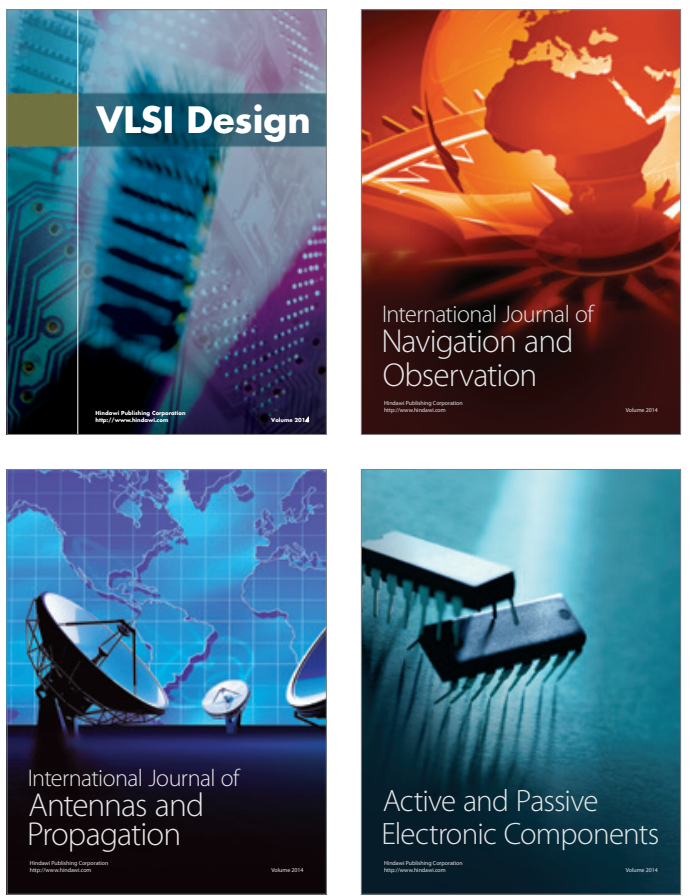
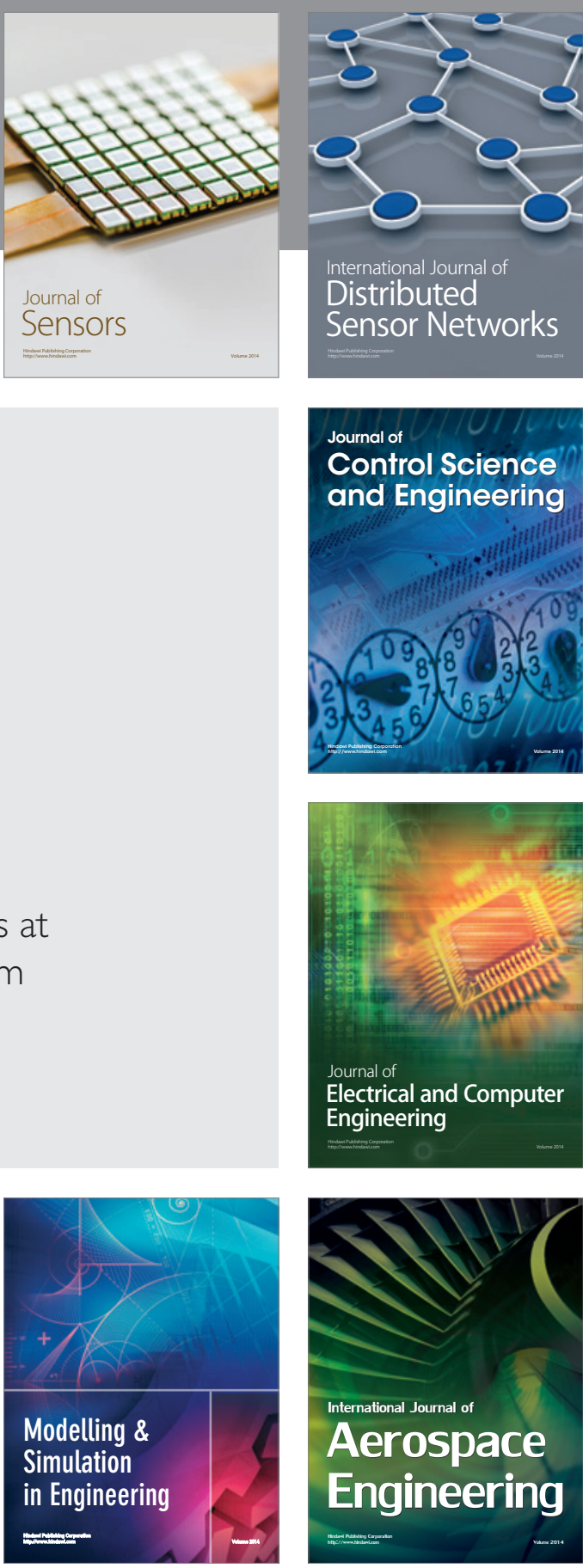

International Journal of

Distributed

Sensor Networks

Journal of

Control Science

and Engineering
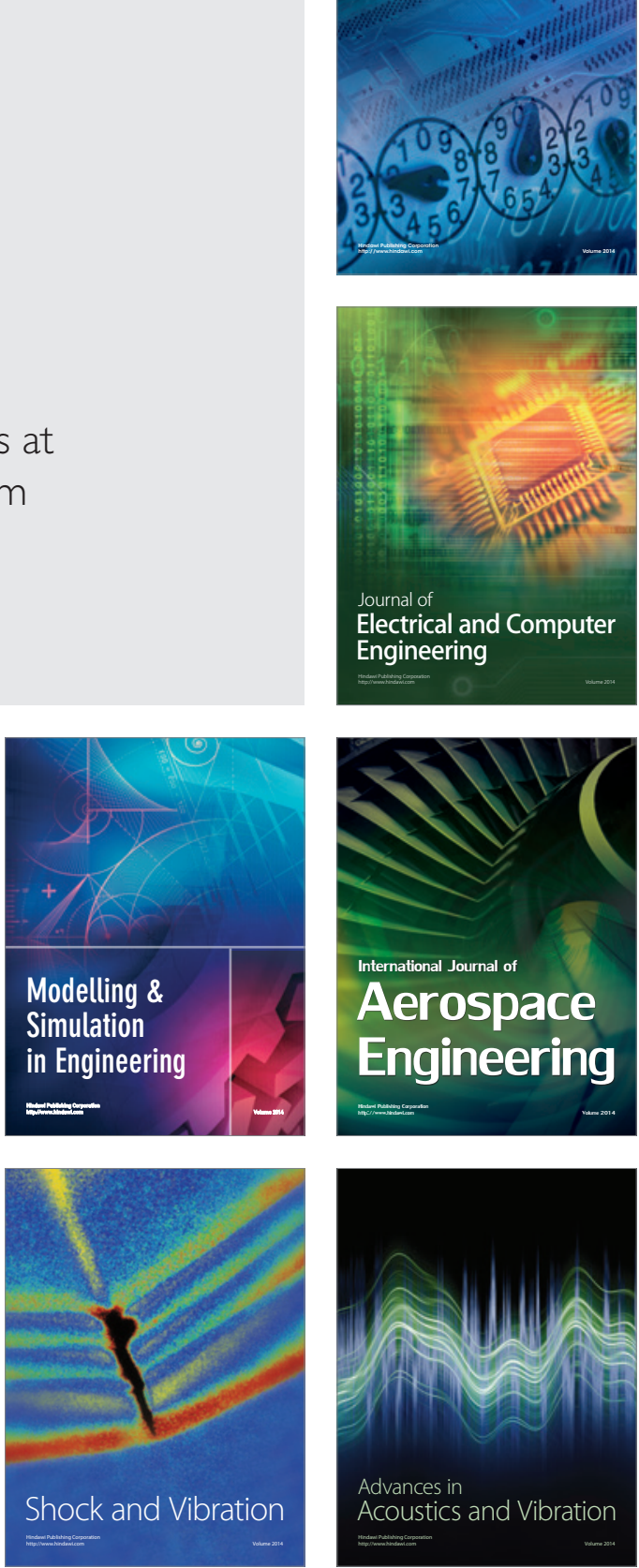